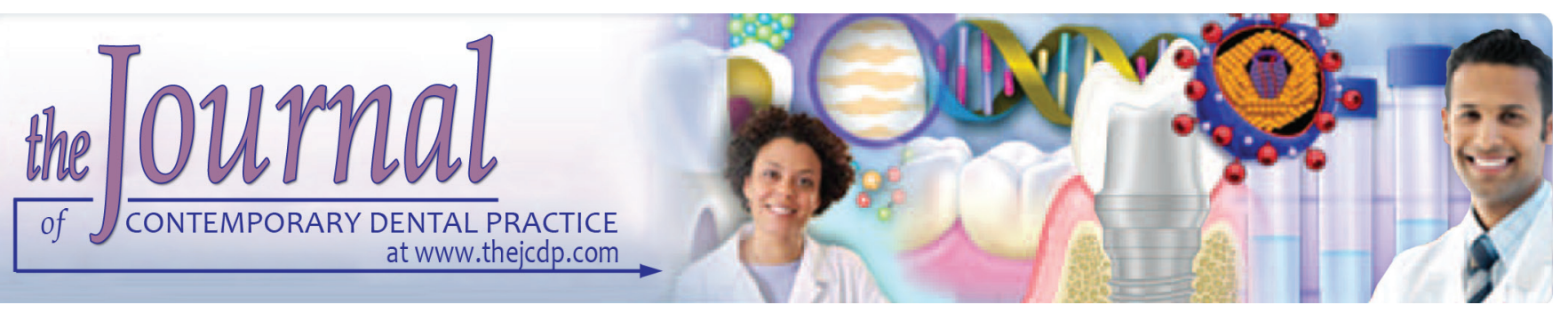

\title{
Effect of Initial Periodontal Therapy on Serum Nitric Oxide Levels in Chronic Periodontitis Patients with or without Type 2 Diabetes Mellitus
}

\author{
${ }^{1}$ Gayathri S, ${ }^{2}$ Elizabeth Koshi, ${ }^{3}$ Arun Sadasivan, ${ }^{4}$ Arunima PR, ${ }^{5}$ Jaya Kumar K
}

\begin{abstract}
Aim: To evaluate the effect of initial periodontal therapy on serum NO levels in chronic periodontitis (CP) patients with or without type2 diabetes mellitus (T2DM)
\end{abstract}

Materials and methods: A total of 90 subjects (group I-30 healthy controls, group I-30 CP and group III-30 CP with T2DM) participated in this study. Groups II and III subjects received initial periodontal therapy. Clinical periodontal parameters (OHI-S, GI, PPD, and CAL) and serum NO levels were evaluated at baseline and 4 weeks after initial periodontal therapy. Serum NO levels were determined by the Spectrophotometric assay based on the Griess colorimetric reaction.

Results: Four weeks after initial periodontal therapy both groups II and III exhibited improvement in clinical periodontal parameters (OHI-S, GI, PPD, CAL) and reduction in serum levels of NO from its baseline values (Baseline-Group II: $3.64 \pm 0.53,1.93 \pm 0.30$, $3.29 \pm 0.42,3.60 \pm 0.42,89.21 \pm 1.46$ respectively, group III: $3.66 \pm 0.44,2.03 \pm 1.32,3.57 \pm 0.40,3.65 \pm 0.45,85.54 \pm 1.54$ respectively. Post-treatment-Group II: $1.73 \pm 0.42,1.27 \pm 0.23$, $3.16 \pm 0.46,3.47 \pm 0.58,70.91 \pm 1.68$ respectively, group III: $2.39 \pm 0.49,1.71 \pm 0.33,3.44 \pm 0.42,3.61 \pm 0.48,68.69 \pm 1.17$ respectively). However, statistically significant differences were observed only with $\mathrm{OHI}-(\mathrm{S})$ and serum NO values in both groups II and III $(p<0.05)$. When the baseline values of groups II and III were compared the differences were non-significant except

\footnotetext{
${ }^{1,4}$ Department of Periodontics and Oral Implantology, PMS College of Dental Science and Research, Vattapara, Thiruvananthapuram, Kerala, India

${ }^{2,3}$ Department of Periodontics and Oral Implantology, Sree Mookambika Institute of Dental Sciences, Kulasekharam, Tamil Nadu, India

${ }^{5}$ Department of Biochemistry, PMS College of Dental Science and Research, Vattapara, Thiruvananthapuram, Kerala, India

Corresponding Author: Gayathri S, Department of Periodontics and Oral Implantology, PMS College of Dental Science and Research, Vattapara, Thiruvananthapuram, Kerala, India, Phone: +919895539237, e-mail: gkathu@gmail.com
}

for $\mathrm{GI}(p<0.05)$. However, when the post-treatment clinical periodontal parameters and serum $\mathrm{NO}$ level of groups II and III were compared, statistically significant differences $(p<0.05)$ were observed except for PPD and CAL between the groups.

Conclusion: NO can be utilized as a good indicator of the inflammatory status of the periodontium. Initial periodontal therapy is effective in reducing serum levels of $\mathrm{NO}$ in $\mathrm{CP}$ patients with or without T2DM.

Clinical significance: A bidirectional relationship exists between periodontal disease and diabetes mellitus. NO is found to play a significant role in the pathobiology of both $\mathrm{CP}$ and T2DM. Initial periodontal therapy seems to be beneficial in reducing serum $\mathrm{NO}$ levels along with periodontal parameters in CP patients with or without T2DM. However further studies are warranted to enhance our knowledge about the role of NO in periodontal diseases in the course of diabetes.

Keywords: Chronic periodontitis, Initial periodontal therapy, Serum NO, T2DM.

How to cite this article: Gayathri S, Koshi E, Sadasivan A, Arunima PR, Kumar JK. Effect of Initial Periodontal Therapy on Serum Nitric Oxide Levels in Chronic Periodontitis Patients with or without Type 2 Diabetes Mellitus. J Contemp Dent Pract 2019;20(2):197-203.

Source of support: Nil

Conflict of interest: None

\section{INTRODUCTION}

Nitric oxide (NO), a highly reactive gaseous free radical, is essential for a vast spectrum of intracellular and extracellular events in a wide variety of tissues. ${ }^{1} \mathrm{NO}$ was first characterized as an endothelium-derived relaxation factor $^{2}$ and has now emerged as an omnipresent intercellular messenger molecule with important cardiovascular, neurological and immune functions. ${ }^{3,4}$ At low levels, NO is beneficial for several physiological and cellular functions including the regulation of vascular tone, inhibition of platelet adhesion and aggregation and neurotransmission; whereas at higher levels, NO acts 
as a cytotoxic molecule of the nonspecific host defense mechanisms against infectious agents such as bacteria, fungi, and protozoa as well as tumor cells. ${ }^{1,5}$ In recent years, growing evidence suggest that NO, it's metabolites and nitro-oxidative stress play an important role in the progression of inflammatory diseases like periodontitis and diabetes mellitus.

Periodontitis is the most prevalent chronic inflammatory disease of the supporting tissues of the teeth. Bacteria are the primary etiologic factors in the pathogenesis of the periodontal disease. Once these bacterial virulence factors overwhelm the local defense mechanisms; they stimulate a cascade of inflammatory reactions in the host, resulting in the loss of toothsupporting structures. The initial host responses the release of free radicals, via the metabolic process of respiratory burst in the polymorphonuclear neutrophils (PMNL), macrophages and monocytes. These migrating white blood cells enhance the expression of induced nitric oxide synthase (iNOS). ${ }^{6,7}$ Activation of iNOS leads to increased production of NO via iNOS pathway in inflamed periodontal tissues for sustained periods of time. ${ }^{4}$ In addition to this, bacterial lipopolysaccharides also enhance the expression of iNOS in fibroblasts and subsequent rise in $\mathrm{NO}$ production and periodontal destruction. ${ }^{7}$ A plethora of studies investigated the salivary $^{8-12}$ and serum ${ }^{13-15}$ levels of NO in periodontitis patients, but results were often controversial.

Diabetes mellitus (DM) is a metabolic disorder characterized by chronic hyperglycemia resulting from defects in insulin secretion, insulin action, or both. ${ }^{16}$ Hyperglycemia stimulates the production of advanced glycation end products (AGEs), and activates protein kinase $\mathrm{C}$ and enhances the polyol, and hexosamine pathways, resulting in excessive production of superoxide anion $\left(\mathrm{O}_{2-}\right)$, which may lead to oxidative stress. ${ }^{17-20}$ This $\mathrm{O}_{2-}$ react rapidly with $\mathrm{NO}$ radicals, forming the peroxynitrite anion, which is a toxic oxidant capable of damaging several biological molecules, ${ }^{19}$ leading to tissue injury. Hyperglycemia-induced superoxide generation also contributes to the increased expression of nicotinamide adenine dinucleotide phosphate (NADPH) oxidase, an enzyme that catalyzes $\mathrm{O} 2-$ and peroxide generation. Hyperglycemia also favors an increased expression of iNOS, through the activation of nuclear factor $-\kappa \mathrm{B}$, which in turn increase the generation of NO. ${ }^{21}$

It has been reported that there exists a bidirectional relationship between DM and periodontal disease. ${ }^{22,23}$ since these conditions, contribute to each other's severity and worsen each other's prognosis. Periodontal disease is considered the sixth complication of diabetes. ${ }^{24}$ Till date, there are only limited data concerning the influence of serum levels of NO in the inflammatory reactions of periodontium in the course of DM. The aim of our study was to compare the effect of initial periodontal therapy on serum levels of NO in systemically healthy $\mathrm{CP}$ patients and $\mathrm{CP}$ patients with T2DM. To the best of our knowledge, this is the first study evaluating the effect of initial periodontal therapy on serum NO levels in $\mathrm{CP}$ patients.

\section{MATERIALS AND METHODS}

The study population consisted of 90 subjects, aged between 20 years and 70 years, and were categorized into three groups $(n=30)$ : Group-I (Healthy controls), Group-II (Otherwise healthy patients with CP), GroupIII (Patients with CP and T2DM). Approval for the study was obtained from the Institutional Human Ethics Committee, Sree Mookambika Institute of Dental Sciences, Tamil Nadu, India, in accordance with the Helsinki Declaration of 1975, as revised in 2000. The subjects were given a detailed explanation of the study and associated treatment procedures. Written informed consent was obtained from each subject who agreed to participate voluntarily in this study.

The periodontal diagnosis of the subjects with chronic generalized periodontitis (CP) was established based on the clinical criteria proposed by the 1999 world workshop for classification of periodontal diseases and conditions (ie. $\geq 20$ natural teeth with $>30 \%$ of measured sites with clinical attachment loss (CAL) $\geq 4 \mathrm{~mm}$ and probing pocket depth (PPD) $\geq 5 \mathrm{~mm}$ at baseline). ${ }^{25}$ Patients were considered to be well-controlled type 2 diabetic based on the criteria given by American Diabetic Association in 2008 and $\mathrm{HbA} 1 \mathrm{c}$ levels $\leq 7 \% .{ }^{26}$ Healthy subjects without chronic periodontitis and any type of systemic diseases were selected as controls.

Exclusion criteria consisted of patients suffering from any systemic disease (except T2DM); subjects who used anti-inflammatory drugs, antimicrobial drugs, mouthwashes or vitamin supplements within 3 months or underwent periodontal therapy within 6 months; smokers; alcoholics; pregnant or lactating females and subjects with special dietary requirements.

Each subject underwent periodontal probing (using William's graduated periodontal probe) and charting of clinical periodontal parameters including oral hygienesimplified index(OHI-S)-(Greene and Vermillion-1964); gingival index (GI)-(Loe and Silness-1964); probing pocket depth (PPD); and clinical attachment level (CAL). All these clinical periodontal parameters were assessed at six sites per tooth(mesiobuccal, mid-buccal, distobuccal, mesiolingual, mid-lingual, distolingual). The fasting blood sugar (FBS) and $\mathrm{HbA}_{1 \mathrm{c}}$ were also estimated and the patients were assigned into three groups. 
A fasting blood sample (5 mL of venous blood) was collected from the antecubital fossa of each subject by venipuncture using a 20 gauge needle with a $5 \mathrm{~mL}$ syringe, before the periodontal examination. Serum was separated from blood by centrifuging the sample at 3000 rpm for 10 minutes and stored until the biochemical estimation of NO. All the subjects in group II and group III were treated with initial periodontal therapy, including oral hygiene instructions, full mouth scaling, and root planning and were recalled after 4 weeks to evaluate the same clinical and biochemical parameters.

- Biochemical estimation of NO: Spectrophotometric assay based on Griess colorimetric reaction is the most commonly used method for the indirect determination of NO levels, which estimates the level of stable end products of $\mathrm{NO}$ (nitrites $\left(\mathrm{NO}_{2-}\right)$ and nitrates $\left(\mathrm{NO}_{3-}\right)$ ) 27,28 Deproteinization of the serum samples was done by adding zinc sulfate and sodium hydroxide (Fig. 1), followed by centrifugation. Before the Griess reaction, the conversion of $\mathrm{NO}_{3-}$ to $\mathrm{NO}_{2-}$ is required, which was done by adding freshly

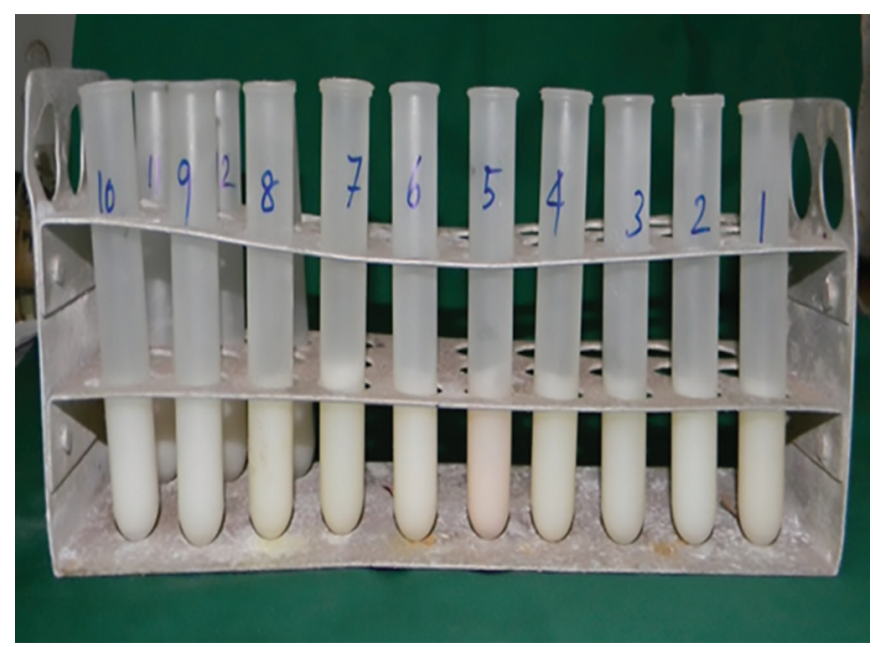

Fig. 1: Deproteinization of the sample was done by adding zinc sulfate and sodium hydroxide

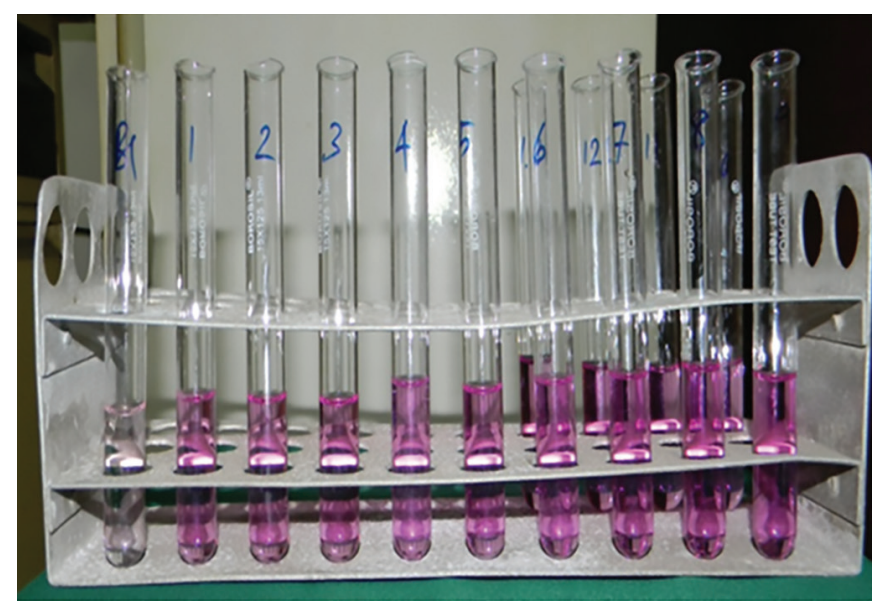

Fig. 3: Griess colorimetric reaction resulted in a purple colored chromophoric azo product prepared copper coated-cadmium granules in each test tube containing the deproteinized sample (Fig. 2). After that this reaction mixture was treated with freshly prepared Griess reagent (1\%sulphanilamide, $0.1 \%$ N-(1-naphthyl) ethylenediamine dihydrochloride and 5\% phosphoric acid) and incubated at room temperature for 10 minutes, resulting in the formation of a purple colored chromophoric azo product (Fig. 3). The optical density (OD) of each reaction mixture was measured using a spectrophotometer (Fig. 4), at 545 $\mathrm{mm}$. These OD readings were compared to a standard curve plotted with known standard concentrations of sodium nitrite and the corresponding nitrite concentrations were determined. The results are presented in $\mu \mathrm{mol} /$ liter $(\mu \mathrm{M} / \mathrm{L})$.

\section{Statistical Analysis}

The data obtained was analyzed by a software SPSS (version 16.0). Paired t-test was used to determine the statistical significance within the group comparison (pre and post-treatment). ANOVA was used for multiple comparisons between groups. Post-hoc Test followed by Dunnett's t-test was applied to find out the statistical significance at a $95 \%$ confidence interval. The significance
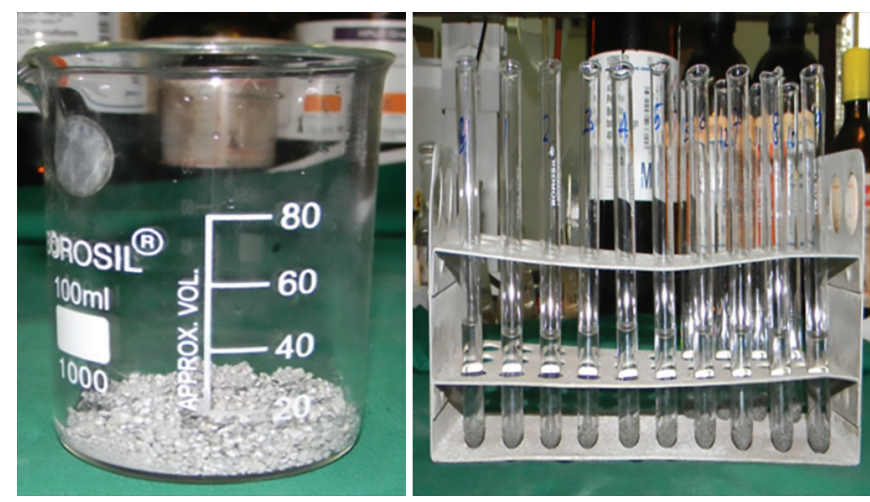

Fig. 2: Freshly prepared copper-cadmium granules for the conversion of $\mathrm{NO}_{3}$ - to $\mathrm{NO}_{2-}$

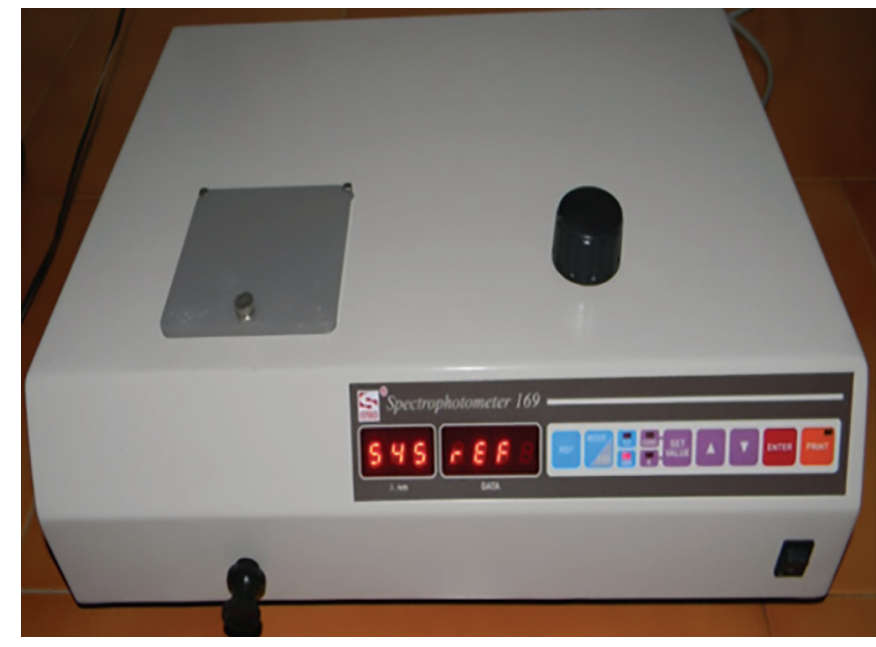

Fig. 4: Spectrophotometer used in the study 
level was set at $p<0.05$. The results are presented as mean \pm standard deviation (Mean $\pm \mathrm{SD}$ ).

\section{RESULTS}

Table 1 shows the demographic data of the study population. Table 2 shows the comparison of pretreatment periodontal parameters and serum $\mathrm{NO}$ levels between groups. Table 3 shows the comparison of posttreatment periodontal parameters and serum NO levels between groups II and III.

At baseline, mean values of all clinical periodontal parameters (OHI-S, GI, PPD, CAL) and serum NO levels were found to be higher in group II $(3.64 \pm 0.53,1.93 \pm 0.30$, $3.29 \pm 0.42,3.60 \pm 0.42,89.21 \pm 1.46$ respectively) and group III $(3.66 \pm 0.44,2.03 \pm 1.32,3.57 \pm 0.40,3.65 \pm 0.45,85.54 \pm$ 1.54 respectively) as compared to group I ( $0.95 \pm 0.52$, $0.69 \pm 0.46,1.65 \pm 0.19,1.65 \pm 0.18,65.23 \pm 1.57$ respectively) and were statistically significant $(p<0.05)$. When groups II and III were compared to higher mean values of clinical parameters were observed in group III. A higher mean value in serum NO level was observed in group II $(89.21 \pm 1.46 \mu \mathrm{M} / \mathrm{L})$ as compared to group III (85.54 $\pm 1.54 \mu \mathrm{M} / \mathrm{L})$. However, when group II and group III were compared the difference was non-significant $(p<0.05)$ except for GI.

Allclinical periodontal parameters and serum NOlevels of group II and group III showed a reduction from baseline to post-treatment visit (Group II-1.73 $\pm 0.42,1.27 \pm 0.23$, $3.16 \pm 0.46,3.47 \pm 0.58,70.91 \pm 1.68$ respectively, group III $-2.39 \pm 0.49,1.71 \pm 0.33,3.44 \pm 0.42,3.61 \pm 0.48,68.69 \pm 1.17$ respectively) and were statistically significant $(p<0.05)$ except for PPD and CAL. When post-treatment clinical periodontal parameters and serum NO level of Group II and Group III were compared, statistically significant differences $(p<0.05)$ were observed except for PPD and CAL.

In both Group II and Group III, statistically significant differences were observed ( $p<0.05)$ with OHI-(S) and serum NO values, when baseline and post-treatment values of all clinical periodontal parameters and serum NO levels were compared within the groups.

\section{DISCUSSION}

Over the past few decades, a large number of studies investigated the relationship between DM and periodontitis clinically, but outcomes were often controversial. ${ }^{26-32}$ the present study was conducted to find out the effect of initial periodontal therapy on serum levels of NO in systemically healthy CP patients and in CP patients with T2DM.

NO plays an important role in inflammatory processes, being an endogenous regulator of vascular tone. ${ }^{33}$ In mammals, NO is synthesized by a group of enzymes called nitric oxide synthases (NOS), which oxidize the amino acid L-arginine into NO and L-citrulline in NADPH dependent manner. The isoforms of NOS are:

- Endothelial NOS (eNOS): Initially detected in the vascular endothelium,

- Neuronal NOS ( $n N O S$ ): Present in the peripheral and central nervous systems,

- Inducible NOS (iNOS): Iinduced in various cell types, including macrophages, kupffer cells, hepatocytes, neutrophils, and fibroblasts, by various inflammatory mediators, such as cytokines and endotoxins. The eNOS and bNOS are constitutive (named cNOS) and $\mathrm{Ca}_{2+} /$ calmodulin-dependent enzymes. ${ }^{1,3}$ cNOS have transient activities and thus release small quantities of NO for a short period in response to

Table 1: Demographic data of the study population

\begin{tabular}{lllllllll}
\hline Groups & $N$ & Male & Female & $21-30 Y$ & $31-40 Y$ & $41-50 Y$ & $51-60 Y$ & $61-70 Y$ \\
\hline Group I & 30 & 13 & 17 & 17 & 10 & 3 & 0 & 0 \\
Group II & 30 & 14 & 16 & 0 & 9 & 12 & 7 & 2 \\
Group III & 30 & 18 & 12 & 0 & 7 & 8 & 12 & 3 \\
\hline
\end{tabular}

Table 2: Comparison of the mean pretreatment periodontal parameters and serum levels of NO between groups

\begin{tabular}{lllll}
\hline Groups & $\begin{array}{l}\text { OHI-S } \\
(M e a n \pm S D)\end{array}$ & $\begin{array}{l}\text { Gingival Index } \\
(\text { Mean } \pm S D)\end{array}$ & $\begin{array}{l}\text { PPD }(\mathrm{mm}) \\
(\text { Mean } \pm S D)\end{array}$ & $\begin{array}{l}\text { CAL }(\mathrm{mm}) \\
(\text { Mean } \pm S D)\end{array}$ \\
\hline Group I & $0.95 \pm 0.52$ & $0.69 \pm 0.46$ & $1.65 \pm 0.19$ & $1.65 \pm 0.18$ \\
Group II & $3.64 \pm 0.53^{*}$ & $1.93 \pm 0.30^{*}$ & $3.29 \pm 0.42^{*}$ & $3.60 \pm 0.42^{*}$ \\
Group III & $3.66 \pm 0.44^{*}$ & $2.03 \pm 1.32^{*}, \#$ & $3.57 \pm 0.40^{*}$ & $3.65 \pm 0.45^{*}$ \\
\hline
\end{tabular}

$\left({ }^{*} p<0.05\right.$ significant, when group-I is compared with other groups, \# $\mathrm{p}<0.05$ significant when group-II is compared with group-III)

Table 3: Comparison of the mean post-treatment periodontal parameters and serum levels of NO between groups II and III

\begin{tabular}{lllll}
\hline Groups & $\begin{array}{l}\text { OHI-S } \\
(\text { Mean } \pm S D)\end{array}$ & $\begin{array}{l}\text { Gingival index } \\
\text { (Mean } \pm S D)\end{array}$ & $\begin{array}{l}\text { PPD }(\mathrm{mm}) \\
(\text { Mean } \pm \text { SD) }\end{array}$ & $\begin{array}{l}\text { CAL }(\mathrm{mm}) \\
(\text { Mean } \pm S D)\end{array}$ \\
\hline Group II & $1.73 \pm 0.42$ & $1.27 \pm 0.23$ & $3.16 \pm 0.46$ & $3.47 \pm 0.58$ \\
Group III & $2.39 \pm 0.49 \#$ & $1.71 \pm 0.33 \#$ & $3.44 \pm 0.42$ & $3.61 \pm 0.48$ \\
\hline (\# $p<0.05$ significant-when $\pm S D)$
\end{tabular}

(\# $p<0.05$ significant-when group II is compared with group III) 
receptor stimulation. In contrast, iNOS is long lasting and generates large quantities of $\mathrm{NO}$ in response to proinflammatory stimuli for a sustained time period. 1,34,35 Blood levels of $\mathrm{NO}$ are influenced by gender, age, and nutrition in healthy subjects. ${ }^{36}$ Once formed, NO is rapidly oxidized into its stable products, $\mathrm{NO}_{2-}$ and nitrates $\mathrm{NO}_{3-}$ (collectively termed $\mathrm{NOx}$ ). ${ }^{1} \mathrm{NO}$ and $\mathrm{NOx}$ readily react with $\mathrm{O}_{2-}$ (to form peroxynitrite), thiols (to form S-nitrosothiols), secondary amines (to form N-nitrosamines), and metals (to form nitrosyl-heme). ${ }^{35}$ It has been proposed that peroxynitrite is responsible for many of the cytotoxic effects previously attributed to $\mathrm{NO}$ and $\mathrm{O}_{2-}$ and causes lipid peroxidation, damage to proteins and nucleic acids, and results in DNA strand breaks. ${ }^{37}$ In the present study, at baseline, we observed a higher mean value in the serum levels of NO in group II (89.21 \pm $1.46 \mu \mathrm{M} / \mathrm{L})$ when compared to group III $(85.54 \pm 1.54$ $\mu \mathrm{M} / \mathrm{L})$ and the group $\mathrm{I}(65.23 \pm 1.57 \mu \mathrm{M} / \mathrm{L})$. This is in accordance with a previous study 13 where increased $\mathrm{NO}$ levels were found in saliva and GCF of subjects with CP as compared to healthy subjects. Elevated NO production in CP is a reflection of an immune-activated state on which inflammatory cytokines and other mediators are upregulated. ${ }^{1} \mathrm{NO}$ is known to potentiate matrix degradation by suppressing proteoglycan and collagen synthesis ${ }^{38}$ and up-regulating matrix metalloproteinases (MMPs) activity. ${ }^{39} \mathrm{NO}$ production modulates the expression of MMPs and down-regulates the synthesis of tissue inhibitors of MMPs causing periodontal tissue destruction. ${ }^{39,40} \mathrm{NO}$ has also been shown to stimulate osteoclast differentiation and osteoclastic activity; ${ }^{41}$ and activate cycloxygenase (COX) enzyme leading to increased prostaglandin $\mathrm{E}_{2},{ }^{42}$ resulting in enhanced periodontitis-induced bone resorption.

At baseline, the lower mean value of serum NO levels was observed in group III $(85.54 \pm 1.54 \mu \mathrm{M} / \mathrm{L})$ compared to group II $(89.21 \pm 1.46 \mu \mathrm{M} / \mathrm{L})$ in our study, which was statistically significant $(p<0.05)$. This might be due to the impaired circulation observed in diabetic patients which limits the availability of NOS and NO. It has been reported that glycosylation of hemoglobin impairs the NO vasodilator function of RBC. Glycosylated hemoglobin $\left(\mathrm{HbA}_{1 \mathrm{c}}\right)$ binds $\mathrm{NO}$ in the form of nitrosothiols very tightly so that any NO that is formed cannot be easily released from RBC and aggravates the consequences of endothelial dysfunction in DM. ${ }^{43}$ Moreover, there is evidence that AGEs can have an inhibitory action on NO. AGEs reduce the half-life of eNOS mRNA through an increased rate of mRNA degradation and reduced eNOS activity and impair NO production via the binding of CML ( $\mathrm{N}^{\varepsilon}$--(carboxymethyl) lysine) residues to endothelial AGE receptors, causing a reduction in phosphorylation of serine residues in eNOS, resulting in deactivation of the enzyme. ${ }^{44}$

Studies have shown that hyperglycemia-induced oxidative stress increases asymmetrical dimethylarginine (ADMA), an endogenous inhibitor of NO synthesis, in T2DM. Oxidative stress can reduce the bioavailability of NO and activation of the polyol pathway, which increases the use of NADP, can reduce the biosynthesis of NO. ${ }^{43,45,46}$ It has also been reported that the kidney dysfunction associated with DM may prevent the elimination of major NOS inhibitor ADMA thereby limiting the production of NO in T2DM patients. ${ }^{43}$

In the present study, the periodontal parameters like OHI-S, GI, PPD and CAL values were higher in group III at baseline with mean values: $3.66 \pm 0.44,2.03 \pm 1.32$, $3.57 \pm 0.40 \mathrm{~mm}, 3.65 \pm 0.45 \mathrm{~mm}$ respectively as compared to group I and group II. At baseline, there was no significant difference for the periodontal parameters between group II and group III except for GI with a mean value of $2.03 \pm 1.32$ $(p<0.05)$ in group III when compared to $1.93 \pm 0.30$ in group II. This was in agreement with the study of Nowak et al. ${ }^{47}$ where clinical parameters such as PI, GI, PD and CAL values were higher in patients with DM and periodontitis compared to patients with only CP. Several mechanisms have been proposed to explain the greater incidence and severity of periodontal disease in patients with diabetes, including PMNL changes, deregulated cytokine dysfunction, vascular changes, altered collagen, and glycosaminoglycans synthesis, and the formation of AGEs. ${ }^{48}$ AGEs with markers for increased oxidative stress have been demonstrated in human gingiva of subjects with CP and DM. ${ }^{49}$

Our study was an interventional study in which all the clinical parameters and serum NO levels were re-estimated 4 weeks after initial periodontal therapy in group II and group III. Results showed a reduction in all the clinical parameters -OHI-S, GI, PPD, CAL- in both group II and group III. However, the reductions in OHI-S and GI values were statistically significant $(p<0.05)$. This is in agreement with previous studies ${ }^{50,51}$ in which initial periodontal therapy was associated with improved periodontal health in T2DM patients. The post-treatment serum NO level in group II and group III also showed a decline from its baseline values and a statistically significant reduction was observed in group II compared to group III. However, there is no evidence to support the influence of initial periodontal therapy in lowering the serum levels of $\mathrm{NO}$ in $\mathrm{CP}$ with or T2DM.

Selective inhibitors of iNOS-mercapto ethyl guanidine, guanido ethyl disulfide, aminoguanidine- were shown to reduce peroxynitrite formation as well as inhibiting prostaglandin production via inhibition of COX. ${ }^{52-54}$ It is therefore logical that modulation of NO might be useful 
in the treatment of chronic inflammatory diseases like periodontal disease and DM. The limitations of this study are related to the less sample size; mismatched male to female ratio and the wide age range of the subjects participated.

\section{CONCLUSION}

Within the limitations, the results of our study indicated higher levels of serum NO in CP patients with or without T2DM at baseline, which got reduced after initial periodontal therapy. Therefore, initial periodontal therapy is beneficial in reducing serum NO levels. It can be speculated that NO may be involved in the pathogenesis of periodontitis and serum NO levels can be utilized as a good indicator of the inflammatory status of the periodontium. In addition, this study also provides more evidence to the link between T2DM and periodontal disease. However, further studies are warranted to enhance our knowledge about the role of NO in periodontal disease in the course of diabetes and to find out whether the administration of chemical inhibitors of NOS combined with initial periodontal therapy can be of some help in modulating host response in the treatment of periodontal disease.

\section{ACKNOWLEDGMENTS}

The authors would like to acknowledge Dr Pradeep CG MSc, PhD. for the technical help provided for the biochemical analysis. We would also like to thank $\mathrm{Mr}$ K Sarath Babu, for helping us with the timely statistical analysis involved in this study.

\section{REFERENCES}

1. Kendall HK, Marshall RI, Bartold PM. Nitric oxide and tissue destruction. Oral Dis 2001;7(1):2-10.

2. Moncada S, Herman AG, Vanhoutte P. Endothelium-derived relaxing factor is identified as nitric oxide.TIPS 1987; 8(10):365-368.

3. Nathan C. Nitric oxide as a secretory product of mammalian cell. FASEB J 1992;6:3051-3064.

4. Moncada S, Palmer RM, Higgs EA. Nitric oxide: physiology, pathophysiology, and pharmacology. Pharmacol Rev 1991; 43(2):109-142.

5. Kröncke KD, Fehsel K, Kolb-Bachofen V. Nitric oxide: cytotoxicity versus cytoprotection-how, why, when, and where? Nitric Oxide 1997;1(2):107-120.

6. Kim YS, Pi SH, Lee YM, Lee SI, Kim EC. The anti-inflammatory role of heme oxygenase-1 in lipopolysaccharide and cytokine-stimulated inducible nitric oxide synthase and nitric oxide production in human periodontal ligament cells. J Periodontol. 2009;80(12):2045-2055.

7. Batista AC, Silva TA, Chun JH, Lara VS. Nitric oxide synthesis and severity of human periodontal disease. Oral Dis. $2002 ; 8(5): 254-260$.
8. Matejka M, Partyka L, Ulm C, Solar P, Sinzinger H. Nitric oxide synthesis is increased in periodontal disease. J Periodontal Res 1998; 33(8):517-518.

9. Aurer A, Aleksic J, Ivic-Kardum M, Aurer J, Culo F. Nitric oxide synthesis is decreased in periodontitis. J Clin Periodontol 2001; 28(6):565-568.

10. Reher VG, Zenobio EG, Costa FO, Reher P, Soares RV. Nitric oxide levels in saliva increase with severity of chronic periodontitis. J Oral Sci2007; 49(4):271-276.

11. Ozer L, Elgun S, Ozdemir B, Pervane B, Ozmeric N Argininenitric oxide-polyamine metabolism in periodontal disease. J Periodontol 2011;82(2):320-328.

12. Parwani SR, Chitnis PJ, Parwani RN. Salivary nitric oxide levels in inflammatory periodontal disease-A case-control and interventional study. Int J Dent Hyg 2012;10(1):67-73.

13. Menaka KB, Ramesh A, Thomas B \& Kumari NS. Estimation of nitric oxide as an inflammatory marker in periodontitis. Journal of Indian Society of Periodontology 2009; 13(2):75-78.

14. Andrukhov O, Haririan H, Bertl K, Rausch WD, Bantleon HP, Moritz A,et al. Nitric oxide production, systemic inflammation and lipid metabolism in periodontitis patients: possible gender aspect. J Clin Periodontol 2013;40(10):916-923.

15. Wattamwar PP, Kolte RA, Kolte AP, Shah KK. Influence of interventional nonsurgical periodontal treatment on levels of salivary and serum nitric oxide in smokers and non-smokers with chronic periodontitis. Journal of Indian Society of Periodontology 2016;20(6):592-596.

16. American Diabetes Association Diagnosis and classification of diabetes mellitus. Diabetes Care 2012;35 (Suppl 1):S64-S71.

17. Brownlee M. The pathobiology of diabetic complications: a unifying mechanism. Diabetes 2005; 54(6):1615-1625.

18. Ruderman NB, Williamson JR, Brownlee M. Glucose and diabetic vascular disease. FASEB J 1992; 6: 2905-2914.

19. Pacher P, Beckman JS, Liaudet L. Nitric oxide and peroxynitrite in health and disease. Physiol. Rev 2007; 87(1):315-424.

20. Nassar H, Kantarci A, and Van DykeTE. Diabetic periodontitis: a model for activated innate immunity and impaired resolution of inflammation. Periodontol 2000 2007;43(1): 233-244.

21. Pacher P, Obrosova IG, Mabley JG and Szabó C.Role of Nitrosative Stress and Peroxynitrite in the Pathogenesis of Diabetic Complications. Emerging New Therapeutical Strategies. Curr Med Chem 2005;12(3):267-275.

22. Grossi SG, Genco RJ. Periodontal disease and diabetes mellitus: a two-way relationship. Ann Periodontol 1998;3(1):51-61.

23. Preshaw PM, Alba AL, Herrera D, Jepsen S, Konstantinidis A, Makrilakis K. et al.Periodontitis and diabetes: a two-way relationship. Diabetologia. 2012;55(1):21-31.

24. Loe H. Periodontal disease. The sixth complication of diabetes mellitus. Diabetes Care 1993 16(1):329-334.

25. Armitage GC. Development of a classification system for periodontal diseases and Conditions. Ann Periodontol 1999; 4(1):1-6.

26. Pan Z, Guzeldemir E, Toygar HU, Bal N and Bulut S. Nitric oxide synthase in gingival tissues of patients with chronic periodontitis and with and without diabetes. J Periodontol 2010;81(1):109-110.

27. Cortas N, Wakid N. Determination of inorganic nitrate in serum and urine by a kinetic cadmium- reduction method. Clin Chem 1990;36(8):1440-1443.

28. Bryan NS, Grisham MB. Methods to detect Nitric Oxide and its Metabolites in Biological Samples. Free Radic Biol Med 2007; 43(5):645-657. 
29. Shlossman M, Knowler WC, Pettitt DJ, Genco RJ. Type 2 diabetes mellitus and periodontal disease. J Am Dent Assoc 1990;121(4):532-536.

30. Kiran M, Arpak N, Unsal E, Erdogan MF. The effect of improved periodontal health on metabolic control in type 2 diabetes mellitus. J Clin Periodontol 2005;32(3):266-272.

31. Garcia R. Periodontal treatment could improve glycaemic control in diabetic patients. Evid Based Dent 2009; 10(1): 20-21.

32. Promsudthi A, Pimapansri S, Deerochanawong C, Kanchanavasita $W$. The effect of periodontal therapy on uncontrolled type 2 diabetes mellitus in older subjects. Oral Dis 2005; 11(5):293-298.

33. Cirino G, Distrutti E, Wallace JL. Nitric oxide and inflammation. Inflamm Allergy Drug Targets. 2006 Apr; 5(2):115-119.

34. Lohinai ZM, Szabo C. Role of nitric oxide in physiology and pathophysiology of periodontal tissues Med Sci Monit 1998; 4(6):1089-1095.

35. Mian AI, Aranke M, Bryan NS. Nitric Oxide and its Metabolites in the Critical Phase of Illness: Rapid Biomarkers in the Making.Open Biochem J. 2013;7:24-32.

36. Ghasemi A, Zahediasl S. Is nitric oxide a hormone? Iranian Biomed J 2011;15(3):59-65.

37. Szabo C. Multiple pathways of peroxynitrite cytotoxicity. Toxicol Lett 2003;140-141:105-112.

38. Taskiran D, Stefanovic-Racic M, Georgescu H, Evans C. Nitric oxide mediates suppression of cartilage proteoglycan synthesis by interleukin-1. Biochem Biophys Res Commun 1994;15; 200(1);142-148.

39. Brennan PA, Thomas GJ, Langdon JD. The role of nitric oxide in oral diseases. Arch Oral Biol 2003;48(2):93-100.

40. Güllü C, Ozmeric N, Tokman B, Elgün S, Balos K. Effectiveness of scaling and root planing versus modified Widman flap on nitric oxide synthase and arginase activity in patients with chronic periodontitis. J Periodontal Res. 2005 Apr;40(2):168-175.

41. Herrera BS, Martins-Porto R, Maia-Dantas A, Campi P, Spolidorio LC, Costa SKP, et al. iNOS-Derived Nitric Oxide Stimulates Osteoclast Activity and Alveolar Bone Loss in Ligature-Induced Periodontitis in Rats. J Periodontol 2011;82(11):1608-1615.

42. Salvemini D, Seibert K, Masferrer JL, Misko TP, Currie MG. Endogenous nitric oxide enhances prostaglandin production in a model of renal inflammation;J Clin Invest 1994;93(5): 1940-1947.
43. Burke T. Nitric oxide and its role in health and diabetes; Available at www.photonicenergetics.com:1-21.

44. Goldin A, Beckman JA, Schmidt AM, Creager MA. Advanced glycation end products: sparking the development of diabetic vascular injury. Circulation 2006; 114(6):597-605.

45. MahfouzMH,Emara IA, Shouman MS, EzzMK; Asymmetrical dimethylarginine (ADMA) and nitric oxide as potential cardiovascular risk factors in type 2 diabetes mellitus. African Journal of Biochemistry Research 2009; 3(8):293-301.

46. Chan NN, Chan JC. Asymmetric dimethylarginine (ADMA): a potential link between endothelial dysfunction and cardiovascular diseases in insulin resistance syndrome? Diabetologia 2002;45(12):1609-1616.

47. Novak MJ, Potter RM, Blodgett J, Ebersole JL. Periodontal disease in Hispanic Americans with type 2 diabetes. J Periodontol 2008;79(4):629-636.

48. Mealey BL. Periodontal disease and diabetes: A two-way street. JADA 2006; 137 Suppl.:26s-31s.

49. Schmidt AM, Weidman E, Lalla E, Yan SD, Hori O, Cao R, et al. Advanced end products (AGEs) induce oxidant stress in the gingiva: A potential mechanism underlying accelerated periodontal disease associated with diabetes. J Periodontal Res 1996; 31(7):508-515.

50. Rodrigues DC, Taba MJ, Novaes AB, Souza SL, Grisi MF. Effect of non-surgical periodontal therapy on glycemic control in patients with type 2 diabetes mellitus. J Periodontol. 2003;74(9):1361-1367.

51. Koromantzos PA, Makrilakis K, Dereka X, Katsilambros N, Vrotsos IA, Madianos PN. A randomized- controlled trial on the effect of non-surgical periodontal therapy in patients with type 2 diabetes. Part I: Effect on periodontal status and glycaemic control. J Clin Periodontol 2011;38(2):142-147.

52. Arrington H. Inducible Nitric Oxide Synthase and Periodontal Inflammation:A Preclinical Canine Study-Thesis 2007:1-98.

53. Leitao RFC, Ribeiro RA, Chaves HV, Rocha FAC, Lima V, Brito GAC. Nitric oxide synthase inhibition prevents alveolar bone resorption in experimental periodontitis in rats. J Periodontol 2005;76(6):956-963.

54. Zingarelli B, Southan GJ, Gilad E, O'Connor M, Salzman AL, Szabo C.The inhibitory effects of mercaptoalkylguanidines on cyclo-oxygenase activity.Br J Pharmaco. 1997; 120(3):357366. 